\title{
Study on the Evaluation of Teaching Quality of College Teachers with Graduate Students as Study Samples
}

\author{
Yang WANG, Zhifa ZHU \\ School of Management, China University of Mining and Technology, Beijing
}

\begin{abstract}
This paper have choose the university graduate student as the main body of the 53 samples of the teaching quality and moral quality evaluation index selection, and every questionnaire is valid. The process and result have proved that graduate students paid much concern about our research, and expressed their views which mainly reflected in indicators. Through the questionnaire survey, building the performance evaluation system of teachers in our school is very necessary and urgent, which will play an important role in improving the overall teaching level.
\end{abstract}

Keywords - Graduate students. University teachers. The evaluation system of teacher performance

\section{Literature Review}

Considering the importance of reasonable and effective performance evaluation of teachers, this paper combined with the school of teacher performance evaluation method and focus on a part of the performance evaluation system of teachers can be quantified Basing on collecting, reading books and literature at home ${ }^{[1]}$. We learn from reasonable part of the performance evaluation system of teachers in the references and summarized the teacher performance evaluation index system that China University of mining \& technology (Beijing) have implemented in order to made a set of new evaluation system for teachers ${ }^{[2]}$. About the part that cannot be quantified in the performance evaluation system for the teachers, Xiebo think that the teachers of establishing evaluation system of evaluation is mainly the teacher's own development as the goal and the evaluation main body covered from top to bottom all populations ${ }^{[3]}$. Xu Shuang through exploratory factor analysis, reliability test, validity analysis, confirmatory factor analysis and a series of studies have shown that good teachers contains teaching effectiveness, moral accomplishment, interaction between teachers and students, feelings, instrument vitality, net ethics quality, a total of six factors ${ }^{[4]}$. In combination, on the basis of existing literature, we have formulated a set of evaluation index. Designed the questionnaire and according to the form and had a questionnaire survey for the graduate of China University of mining \&technology (Beijing). Through summary analysis of the questionnaire content and Finding the student's teacher ideal, we hope to provide beneficial guidance for the teachers' performance rating system in our school.

\section{The Questionnaire Survey Analysis about Graduate Students}

In the process of university faculty performance evaluation, we have designed the following questionnaire in order to solve the problem of some indicators to quantify. This questionnaire is mainly divided into teachers' moral quality and teaching quality. This investigation took the way filling out at the scene and distributed to undergraduate and graduate students in school. The total recovery of 53 questionnaires o The following is described respectively about the statistical results of parts information.

\subsection{University faculties' moral character}

The vote situation and the proportion of all the options about teachers' moral quality as shown in table 1 and figure 1 .

TABLE 2-1 Moral character detail list

\begin{tabular}{|l|c|}
\hline Option & Votes \\
\hline A. Role models, Family harmony & 21 \\
\hline B. High moral character ${ }^{[5]}$ & 27 \\
\hline C. Team spirit, Caring & 9 \\
\hline D. Responsibility, Selfless dedication & 20 \\
\hline E. Patient & 20 \\
\hline F. Easy-going, Understanding & 28 \\
\hline G. Justice, Democracy & 25 \\
\hline H. Encouragement & 7 \\
\hline I. Caring about undergraduates' future & 20 \\
\hline J. Honesty, Integrity & 11 \\
\hline K. Set examples & 16 \\
\hline Total & \\
\hline
\end{tabular}

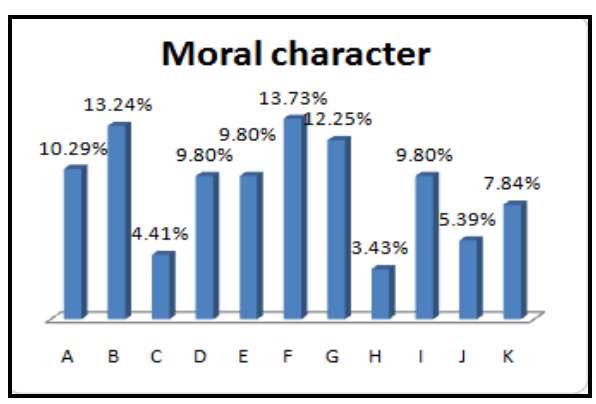

Fig. 2-1 Moral character Ratio

In the indicators of teachers' moral quality, statistics shows that graduate students pay most attention to "F" 、 "B" 、 "A" 、 "G" 、"D" 、"E" 、"I". The vote of index had reached $70.39 \%$ and more than $70 \%$. These findings indicate : An

\footnotetext{
* Fund Projects: National Natural Science Foundation (71373262); Beijing Undergraduate Training Programs for Innovation (Z20141504); Teaching Reform Project of China University of Mining \& Technology, Beijing (j120501).
} 
approachable, fair and understand the student's teacher is easier to get along with students and understand students' needs, which can help students in the classroom theoretical study and extracurricular practice. The graduate students are no exception. (2) Only moral and healthy personalities of teachers in colleges can guide the graduate student correct outlook on life, values and world view.

\subsection{University teachers' personal ability}

The vote situation and the proportion of all the options about teachers' personal ability as shown in table 2 and figure 2.

TABLE 2-2 Personal capacity detail list

\begin{tabular}{|l|c|}
\hline Option & Votes \\
\hline A. Solid theoretical knowledge, High disciplinary expertise & 39 \\
\hline B. Experienced in teaching & 12 \\
\hline C. Updated knowledge, grasp the latest trends & 29 \\
\hline D. Vivid lectures & 23 \\
\hline E. Correctly and skilled lecture, clear communication of ideas & 34 \\
\hline F. The ability to operate modern educational tools & 7 \\
\hline G. Inspiration ability & 20 \\
\hline H. Communication skills & 18 \\
\hline I. Neatly blackboard writing & 1 \\
\hline J. Scientific research ability & 10 \\
\hline K. Core curriculum & 8 \\
\hline L. Broad interests & 5 \\
\hline Total & 206 \\
\hline
\end{tabular}

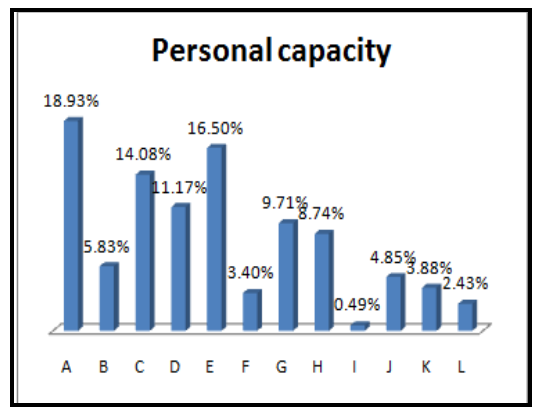

Fig. 2-2 Personal capacity Ratio

In the indicators of teachers' personal ability, statistics shows that graduate students pay most attention to " $\mathrm{A}$ " 、

"C" “G” 、 "E" 、 "D". The vote of index had reached $70.39 \%$ and more than $70 \%$. These findings indicate - (1)Graduate students have a very high demand to the teacher's teaching ability and their theoretical knowledge;(2) In the knowledge era of high speed upgrade, college teachers only by constantly update their knowledge and walk in the forefront of science, can bring to college graduate students innovative thinking.

\subsection{College teachers' psychological quality}

The vote situation and the proportion of all the options about teachers' psychological quality as shown in table 3 and figure 3 .
TABLE 2-3 Psychological quality detail list

\begin{tabular}{|l|c|}
\hline Option & Votes \\
\hline A. Professionalism & 36 \\
\hline B. Scientific research & 15 \\
\hline C. Personal values & 15 \\
\hline D. Intelligent & 8 \\
\hline E. Faith & 11 \\
\hline F. Realistic & 6 \\
\hline G. Personal charm & 12 \\
\hline Total & 103 \\
\hline
\end{tabular}

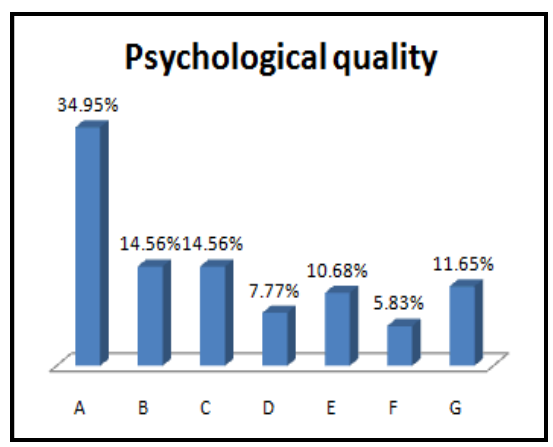

Fig.2-3 Psychological quality Ratio

In the indicators of teachers' psychological quality, statistics shows that graduate students pay most attention to "A" " $C "$ " $G$ " 、 "E" 、 "D" . The vote of index had reached $70.39 \%$ and more than $70 \%$. These findings indicate - (1)It is necessary to have high professional ethics for each college teacher. On the one hand, teachers' moral can has incentive effect on their own. On the other hand, college teachers' professional quality also has very important influence on the formation and development of students' moral consciousness and moral quality.(2) Having a certain scientific research spirit of teachers in colleges can better guide the graduate student learning; philosophy and personal charm of college teachers is an important aspect of recognition and learning of the graduate student ${ }^{[6]}$.

\subsection{The university teachers' teaching attitude}

TABLE2-4 Teaching attitude detail list

\begin{tabular}{|l|c|}
\hline Option & Votes \\
\hline A. Sufficient preparation & 18 \\
\hline B. Punctual & 11 \\
\hline C. Attentive in class & 29 \\
\hline D. Rigorous scholarship & 17 \\
\hline E. Answer students' questions patiently and carefully & 32 \\
\hline F. Consider students' feedback seriously & 20 \\
\hline G. Be strict in student & 3 \\
\hline H. Dedication and responsibility & 19 \\
\hline I. Professionalism & 11 \\
\hline J. Counseling patiently, correcting homework strictly & 9 \\
\hline K. Instruct students individualized & 34 \\
\hline Total & 203 \\
\hline
\end{tabular}




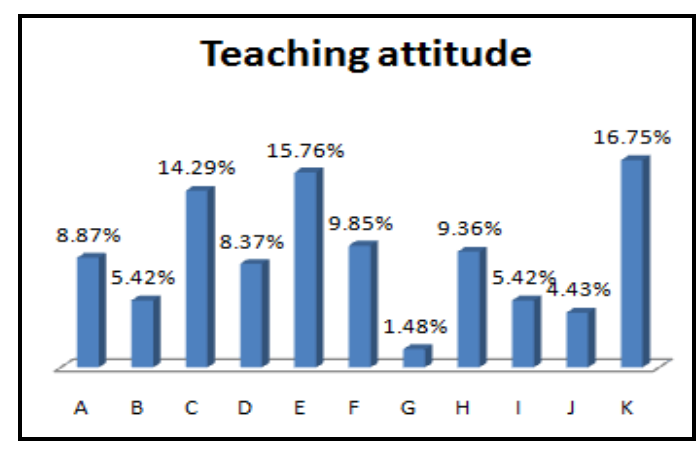

Fig. 2-4Teaching attitude Ratio

The vote situation and the proportion of all the options about teachers' teaching attitude as shown in table 4 and figure 4.

In the indicators of teachers' teaching attitude, statistics shows that graduate students pay most attention to " $\mathrm{A}$ " 、 "C" 、 "K" 、 "F" 、 "H" 、 "E" .The vote of index had reached $70.39 \%$ and more than $70 \%$. These findings indicate - (1)Teaching is the most important ways that teachers teach students knowledge. Teacher's class level and attitude directly affects the student to absorb the knowledge. College students attaches great importance to the index ; (2)It is understandable that students can't fully absorbed the teacher knowledge in the class. Teacher's attitude is vital for students to question after class, which not only affects the student to understand the classroom knowledge further, but also will affect the students' desire for knowledge.

\subsection{University faculties' teaching methods}

The vote situation and the proportion of all the options about teachers' teaching methods as shown in table 5 and figure 5 .

TABLE2-5 Teaching methods detail list

\begin{tabular}{|l|c|}
\hline Option & Votes \\
\hline A. Extensive teaching techniques and methods & 20 \\
\hline B. The lecture is organized, clear and understandable & 27 \\
\hline C. Active class atmosphere & 12 \\
\hline D. The depth and breadth of lectures in line with students & 23 \\
\hline E. Mobilize students' enthusiasm and initiative & 19 \\
\hline $\begin{array}{l}\text { F. Pay attention to teaching quality and students' acceptance } \\
\text { effect }\end{array}$ & 19 \\
\hline $\begin{array}{l}\text { G. Pay attention to internal and external communication and } \\
\text { discussion }\end{array}$ & 19 \\
\hline H. Focus on the relevant parts of teaching process & 7 \\
\hline I. Rational and effective use of various teaching methods & 8 \\
\hline J. Reveal the inherent knowledge of principles & 22 \\
\hline K. Create an orderly learning environment [7] & 6 \\
\hline L. Train basic skills & 15 \\
\hline Total & 197 \\
\hline
\end{tabular}

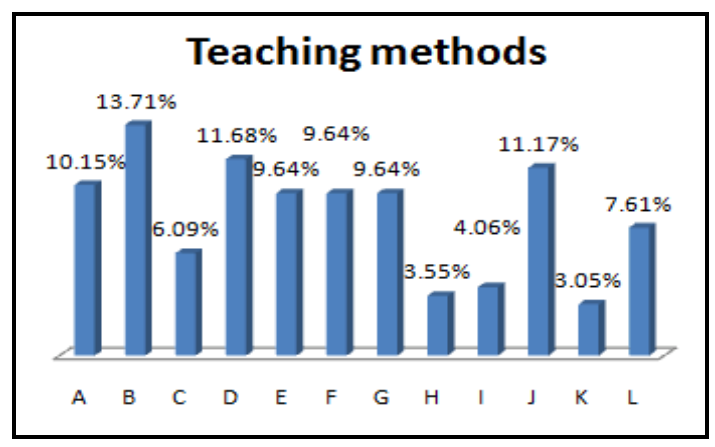

Fig. 2-5Teaching methods Ratio

In the indicators of teachers' teaching methods, statistics shows that graduate students pay most attention to " $\mathrm{A}$ " 、 "B" 、 "D" 、 "J" 、 "F" “ "G" 、 "E". The vote of index had reached $70.39 \%$ and more than $70 \%$.

\subsection{College teacher's instruction after class}

The vote situation and the proportion of all the options about teachers' instruction after class as shown in table 6 and figure 6 .

TABLE2-6 After school tutoring detail list

\begin{tabular}{|l|c|}
\hline Option & Votes \\
\hline A. Care about day life & 12 \\
\hline B. Downsizing homework & 11 \\
\hline C. Participate in extracurricular activities & 7 \\
\hline D. Enrich teaching methods with students' feedback & 32 \\
\hline E. Entre competition activities and thesis supervision & 22 \\
\hline F. Guide internship and social research & 18 \\
\hline Total & 103 \\
\hline
\end{tabular}

\section{After school tutoring}

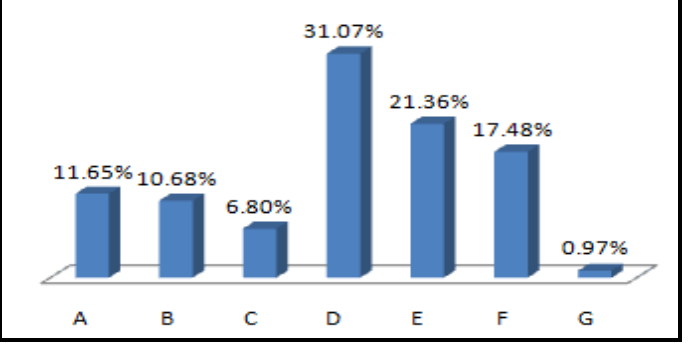

Fig.2-6 After school tutoring Ratio

In the indicators of teachers' instruction after class, statistics shows that graduate students pay most attention to "F" 、 "E" 、 "D". The vote of index had reached $70.39 \%$ and more than $70 \%$. These findings indicate - (1) Perfect teaching methods can improve the effect of teachers' teaching. Accept students teaching feedback could improve teachers' teaching methods, arouse the enthusiasm of the students thinking, increase the emotional communication between teachers and students. 


\subsection{University teachers' teaching effect}

The vote situation and the proportion of all the options about teachers' teaching effect as shown in table 7 and figure 7.

TABLE 2-7 Teaching effect detail list

\begin{tabular}{|l|c|}
\hline Option & Votes \\
\hline A. Choose appropriate textbooks and learning materials & 11 \\
\hline B. Combine theory with practice & 28 \\
\hline C. The quality and ability of students can be greatly improved & 16 \\
\hline D. Teach students the right values and outlook on life & 17 \\
\hline E. Serve as role models & 8 \\
\hline F. Guide individual behaviorism & 19 \\
\hline Total & 99 \\
\hline
\end{tabular}

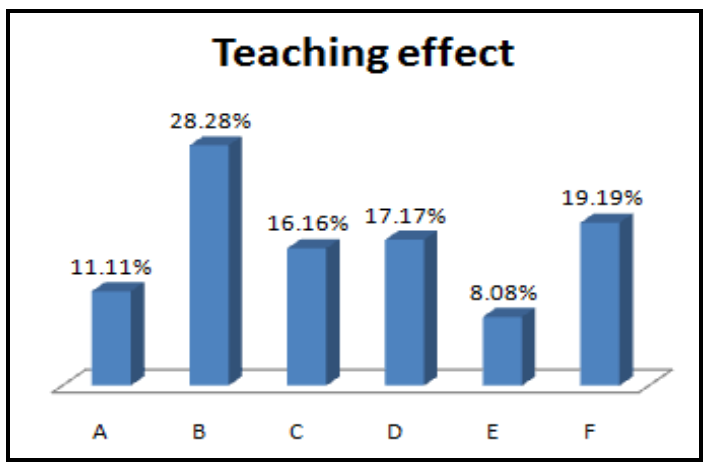

Fig. 2-7 Teaching effect Ratio

In the indicators of teachers' teaching effect, statistics shows that graduate students pay most attention to "B" 、

"F" " $D$ " " $C$ ". The vote of index had reached $70.39 \%$ and more than $70 \%$. These findings indicate $-(1)$ The mode giving priority to with theoretical study can't meet the requirement of university graduate student self-development, how to combine the theory and practice become an important concern to their teachers.

\subsection{The primary task of college teachers}

The vote situation and the proportion of all the options about the primary task of college teachers as shown in table 8 and figure 8 .

TABLE 2-8 primary task detail list

\begin{tabular}{|l|c|}
\hline Option & Votes \\
\hline A. Impart knowledge and cultivate people & 41 \\
\hline B. Scientific research, publish articles & 1 \\
\hline C. Social services, undertaken projects & 2 \\
\hline D. Cultural heritage & 9 \\
\hline Total & 53 \\
\hline
\end{tabular}

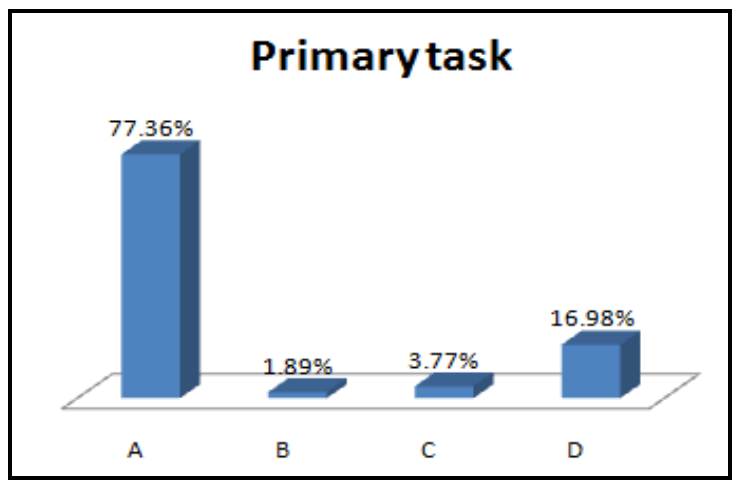

Fig. 2-8 Primary task Ratio

In the indicators of the primary task of college teachers, statistics shows that graduate students pay most attention to "A". The vote of index had reached $70.39 \%$ and more than $70 \%$. These findings indicate-University is an organization of cultivating talents and University teachers is the direct main body of cultivating talents. University teachers' teaching attitude will directly affect the quality of national talent as a whole.

\section{Conclusion}

This paper have choose the university graduate student as the main body of the 53 samples of the teaching quality and moral quality evaluation index selection, and every questionnaire is valid. The process and result have proved that graduate students paid much concern about our research, and expressed their views which mainly reflected in indicators. Through the questionnaire survey, building the performance evaluation system of teachers in our school is very necessary and urgent, which will play an important role in improving the overall teaching level.

\section{References}

[1] Wang Zhihua. Good university teachers college students mind standard. Journal of education, 2008: 61-63

[2] China university of mining \& technology (Beijing) professional technical position qualifications accreditation, 2014: 3-11

[3] Xie Bo. University teachers evaluation system research. Southwest jiao tong university, 2010: 23-27

[4] Xu Shuang. The concept of university students' good teacher research. Chongqing university, 2009: 8-21

[5] China university of mining \&technology (Beijing) rolling funding basic scientific research business expenses project interim measures, 2011: 24

[6] Zhao Baofang, honey, Shi Mingchen. Higher vocational teachers' basic quality and basic ability requirement. Journal of heilongjiang agricultural engineering vocational college, 2007: 12-13

[7] YanYuPing. Comparative study of sino-us teachers evaluation. East China normal university, 2008, 39-41 49 and 50 